\title{
A systemic review of barriers to accessing paediatric eye care services in African countries
}

\author{
Saif Hassan Alrasheed ${ }^{1,2}$
}

1. Department of Optometry, College of Applied Medical Sciences, Qassim University, Saudi Arabia.

2. Faculty of Optometry and Visual Sciences, Department of Binocular vision Al-Neelain University, Khartoum, Sudan.

\begin{abstract}
Background: Global estimate reported that 1.4 million children are blind of which three-quarters live in developing countries. Childhood Visual Impairment is a major public health problem globally especially in rural areas of developing countries. Objective: To review barriers to accessing paediatric eye care services in African countries

Methods: The studies in this review were searched in online databases (PubMed, Web of Sciences, ProQuest, Scopus, Google Scholar, African Index Medicus and Medline) for studies published between January 2000 and April 2020. The articles included in this review, which was conducted in Africa to assess the barriers for accessing paediatric eye care services with regards availability, accessibility, affordability, socio cultural barriers of parents/caregivers and community.

Results: Of 22705 articles screened, the study found 29 publications from 10 African countries which met the inclusion criteria. The main barriers were non-availability, non-accessibility, and non-affordability of paediatric eye care services. The studies reviewed revealed that there are other factors affecting the utilization of paediatric eye services which include the primary health system, geographic barriers, health beliefs, perception of parents; lack of knowledge, attitudes and practices about paediatric eye care. Furthermore, environmental, demographic barriers and socio-economic status has negative impact on accessing paediatric eye care services in African counties.
\end{abstract}

Conclusion: The main barriers to accessing paediatric eye care services in Africa were affordability, accessibility and availability. There is therefore a need for all relevant stakeholders to play a significant role in addressing barriers to child eye care in African countries.

Keywords: Paediatric eye care, Africa, availability, accessibility, affordability, visual impairment, refractive errors.

DOI: https://dx.doi.org/10.4314/ahs.v21i4.47

Cite as: Alrasheed SH. A systemic review of barriers to accessing paediatric eye care services in African countries. Afri Health Sci. 2021;21(4):1887-97. https:/ / dx.doi.org/10.4314/abs.v21i4.47

\section{Introduction}

Global estimates indicate that there are around 19 million visually impaired children worldwide, of these, 1.4 million are blind, and 17.5 million have low vision and most of them are found in developing nations ${ }^{1}$. Global initiative for avoidable blindness reported that the major barrier to accessing paediatric eye care in Africa was unavailability of primary eye health services ${ }^{2,3}$. The World Health Organization (WHO) reported that most of paediatric visual impairment (VI) is treatable by early intervention at primary, secondary, and tertiary level ${ }^{2}$. Of concern, paediatric eye care services in many African countries are not prioritised on the public health

\section{Corresponding author:}

Saif Hassan Alrasheed, Department of Optometry, College of Applied Medical Sciences, Qassim University, Saudi Arabia. Phone numbers: 00966505201475

E-mail: S.rasheed@qu.edu.sa agenda regardless of legislation and guidelines being available, therefore highlighting the fact that barriers to policy development such as politics, poor performing economies and poor health financing systems continue to persists in these countries ${ }^{4-33}$. Although, VI among children is low compared to adults, it has serious significant negative impact on the lifespan of the child with an estimate of $60 \%$ of children dying within one year of becoming blind ${ }^{3,4}$.

Barriers to eye care are broadly defined as factors that affect people from accessing services such as healthcare, which negatively influences both services deliver and access. It is expected that without intervention programs to prevent avoidable childhood blindness; the global loss will be more than US $\$ 110$ billion by the year $2020^{5}$. Children in most instances fail to report their visual limitations while teachers, parents and guardians find it difficult to identify them constituting a barrier to early intervention 4 However, paediatric 
eye care services in the most African countries are inadequate in terms of facilities, equipment, resources, and skilled professionals. For instance, there are only 26 paediatric eye-care centres in sub-Saharan African countries serving 787 million with a ratio of one paediatric eye care centre for 30.3 million children. Available workforce in the African continent is reported to be inadequate and most countries have far less than the optometrist to population required as per the guidelines of the $\mathrm{WHO}^{5-9}$. Moreover, the International Council of Ophthalmologists indicated that two-third of all ophthalmologists worldwide are from high-income countries while the rest of world share the remaining, resulting in inadequate paediatric eye care providers in African countries ${ }^{10,11}$. WHO recommended that at the minimum, there should be one paediatric eye care centre per ten million populations ${ }^{12,13,14}$. In some countries where paediatric eye services exist, they are underutilised because of many existing barriers such as socio economic status, cultural beliefs, unawareness of signs and symptoms1-5 Therefore, barriers leading to poor utilisation of paediatric eye care services in the African region were reviewed in order to address them.

\section{Methodology \\ Systematic search}

The systematic review in this article included all the studies conducted to assess the barriers to accessing paediatric eye care services in African countries from January 2000 to April 2020. Eligible articles were those that: (1) assessed financial barriers (insurance, income, employment status) (2) educational brriers (inability to obtain, influence and perceptions, understanding and using information). The accessibility to paediatric eye care services was assessed by exploring five dimensions:1) availability and accommodation; 2) accessibility; 3) affordability; 4) acceptability; 5) and appropriateness. In order for these dimensions to ensure accessibly, they need to interact (these being: (1) ability to seek, (2) ability to perceive, (3) ability to reach, (4) ability to pay, and (5) ability to engage). The affordability indicator was used in this study to describe the ability of community to pay for cost of paediatric eye care. While the term of accessibility is defined as the ability of community to receive paediatric eye care from primary to tertiary levels. Appropriateness in the current study used to describe paediatric eye care in line with evidence-based or consensus-based.

The studies included cross-sectional epidemiology survey, prospective observational studies, qualitative and quantitative studies. The articles were excluded if (1) they were not conducted in African (2) studies that did not assess barriers to accessing childhood eye care services. The study also excluded, conference paper, meeting abstract, editorial discussion and studies without basic data collection. The articles included in this review were searched online databases Web of sciences, PubMed, ProQuest, Scopus, Google Scholar, African Index Medicus and Medline using the main keywords of search in Table 1.

Table 1: Search keywords used for systemic review of barriers for accessing childhood eye care services in African countries

\begin{tabular}{|l|}
\hline Paediatric eye care services \\
\hline $\begin{array}{l}\text { Visual Impairment/ Vision Impairment* Refractive Error/ Myopia* Avoidable blindness/ Ocular } \\
\text { diseases* Strabismus/ Amblyopia* Eye care services/Visually impaired* }\end{array}$ \\
\hline Barriers for accessing paediatric eye care \\
\hline $\begin{array}{l}\text { Accessibility of paediatric eye care* Health seeking/ Eye care seeking* affordability/ cost* Access/ } \\
\text { Utilize* Availability/ Easy to get eye care* Attitude/ Perceptions* Spectacles wear* Parents/ Caregivers* }\end{array}$ \\
\hline
\end{tabular}




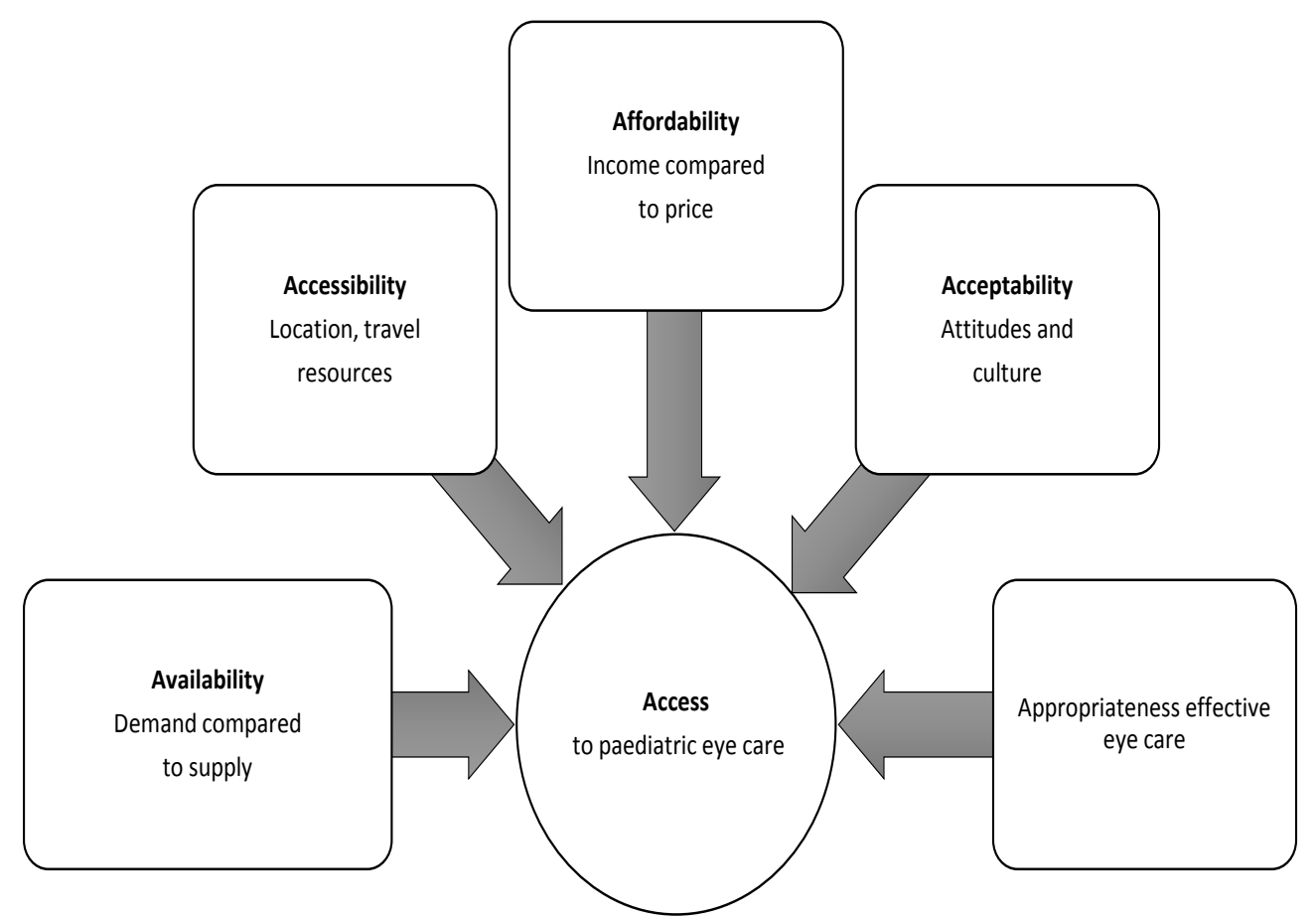

Figure 1: Dimensions of accessibility

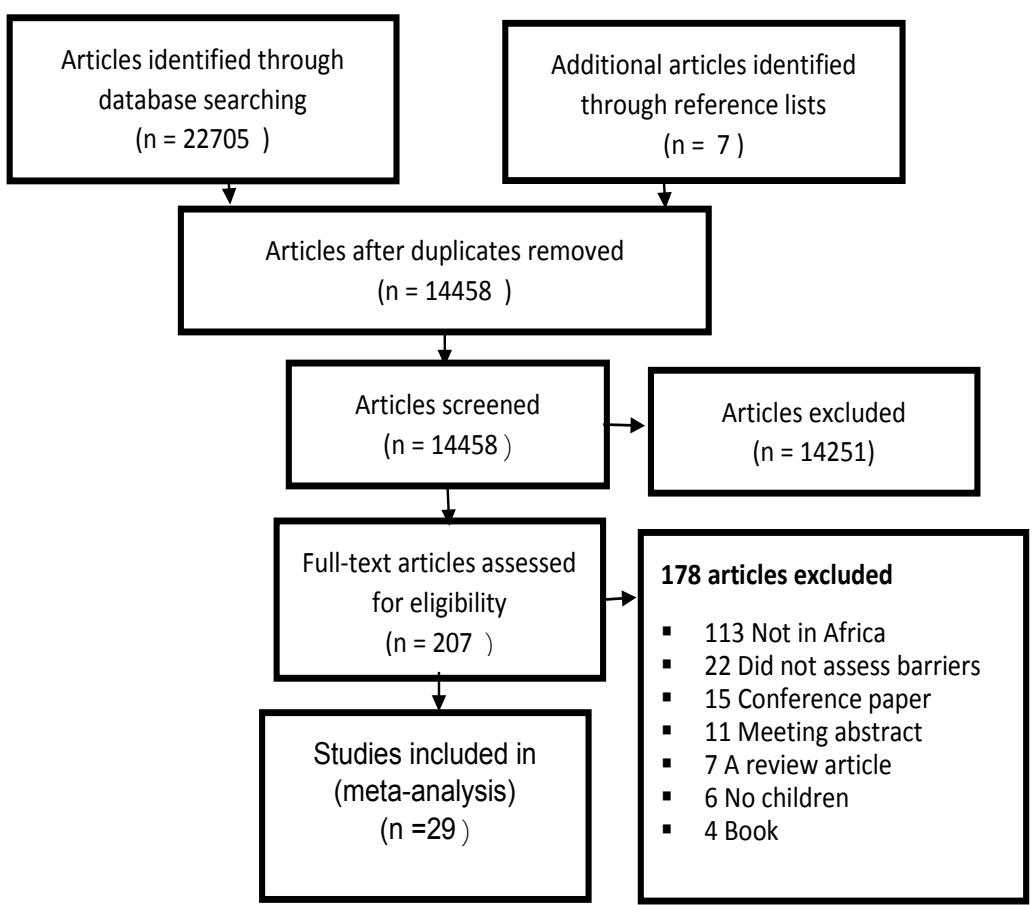

Figure 2: Flowchart used for the systematic review of barriers to accessing paediatric eye care services in African countries

\section{Results}

Of the 22705 articles initially captured, the study found 29 publications from 10 African countries that met the inclusion criteria (Fig.2) ${ }^{12-63}$. The studies reviewed mostly reported that the main barriers were non-availability, non-accessibility, and non-affordability of eye care services in addition to paediatric eye care not being a priority agenda in many Africa health systems ${ }^{6-32}$. The studies reviewed revealed that there are other factors affecting the utilization of paediatric eye services which include the public health system, geographic barriers, health beliefs, perceptions of parents; lack of knowledge, attitudes and practices about childhood eye care. Furthermore, environmental, demographic barriers and socio-economic status has negative impact on accessing paediatric eye care services in African counties ${ }^{32-62}$. 
Table 2: Studies identified in the systemic review about barriers to accessing paediatric eye care services in African countries

\begin{tabular}{|c|c|c|c|c|}
\hline Study & Country & Study design & Study sample & Barriers identified \\
\hline Agarwal et al., $2010^{13}$ & Multi-country & $\begin{array}{l}\text { Cross-sectional } \\
\text { (prospective) }\end{array}$ & $\begin{array}{l}27 \text { health tertiary } \\
\text { facilities }\end{array}$ & $\begin{array}{l}\text { Availability, accessibility and } \\
\text { affordability }\end{array}$ \\
\hline $\begin{array}{l}\text { Alrasheed et al., } \\
2018^{14}\end{array}$ & Sudan & $\begin{array}{l}\text { Qualitative } \\
\text { (Delphi) }\end{array}$ & 18 eye-care providers & $\begin{array}{l}\text { Availability, accessibility and } \\
\text { affordability }\end{array}$ \\
\hline Sukati et al., $2018^{15}$ & Swaziland & Mixed & 9 eye health facilities & $\begin{array}{l}\text { Availability, accessibility and } \\
\text { affordability }\end{array}$ \\
\hline Ebeigbe $2018^{20}$ & Nigeria & $\begin{array}{l}\text { Qualitative } \\
\text { (narrative) }\end{array}$ & $\begin{array}{l}35 \text { parents and } 10 \text { eye- } \\
\text { care practitioners }\end{array}$ & Parents behaviour \\
\hline Alrasheed, et al. $2016^{24}$ & Sudan & $\begin{array}{l}\text { Quantitative and } \\
\text { qualitative } \\
\text { methods }\end{array}$ & $\begin{array}{l}387 \text { Pupils and } 47 \\
\text { parents }\end{array}$ & $\begin{array}{l}\text { KAP of the students and their } \\
\text { parents }\end{array}$ \\
\hline Sukati, et al $20018^{34}$ & Swaziland & Quantitative & 173 parents & KAP of parents \\
\hline Ugalahi, et al $2020^{35}$ & Nigeria & Quantitative & 164 children & affordability \\
\hline Chan, et al $2017^{36}$ & Tanzania & $\begin{array}{l}\text { Quantitative- } \\
\text { (Prospective) }\end{array}$ & 1051 participants & Parents behaviour \\
\hline Sukati, et al $2019^{39}$ & Swaziland & Quantitative & $\begin{array}{l}15 \text { public eye health } \\
\text { professionals }\end{array}$ & $\begin{array}{l}\text { Availability and accessibility of } \\
\text { child eye care services }\end{array}$ \\
\hline $\begin{array}{l}\text { Amiebenomo, et } \\
\text { al } 2016^{40}\end{array}$ & Nigeria & Quantitative & 468 parents & KAP parents \\
\hline Oguego, et al $2018^{41}$ & Nigeria & Quantitative & 833 Students & Eye health misconceptions \\
\hline Nyamai, et al $2016^{42}$ & Kenya & Quantitative & 1390 students & KAP of students towards RE \\
\hline Belaynew, et al $2014^{43}$ & Ethiopia & Quantitative & 1315 households & $\begin{array}{l}\text { KAP of community towards } \\
\text { childhood blindness }\end{array}$ \\
\hline Wanyama $2013^{44}$ & Kenya & Descriptive & 125 pediatricians & $\begin{array}{l}\text { KAP of child eye disease among } \\
\text { pediatricians }\end{array}$ \\
\hline Ayanniyi, et al $2010^{45}$ & Nigeria & Quantitative & 1,393 guardians & $\begin{array}{l}\text { Guardians' attitude towards eye } \\
\text { health }\end{array}$ \\
\hline Kumah, et al $2017^{46}$ & Ghana & $\begin{array}{l}\text { Hospital-based } \\
\text { cross-sectional }\end{array}$ & 100 mothers & $\begin{array}{l}\text { Knowledge } \\
\text { of paediatric blindness among } \\
\text { mothers }\end{array}$ \\
\hline Alemayehu, et al $2018^{47}$ & Ethiopia & $\begin{array}{l}\text { Institution-based } \\
\text { cross-sectional }\end{array}$ & $\begin{array}{l}565 \text { primary school } \\
\text { teachers }\end{array}$ & $\begin{array}{l}\text { KAP and associated factors } \\
\text { among teachers about RE }\end{array}$ \\
\hline Ebeigbe, et al $2017^{48}$ & Nigeria & Qualitative & 35 parents & $\begin{array}{l}\text { Parents knowledge about their } \\
\text { children's eye problems }\end{array}$ \\
\hline Alrasheed et al $2018^{51}$ & Sudan & $\begin{array}{l}\text { School-based } \\
\text { cross-sectional }\end{array}$ & $\begin{array}{l}387 \text { Students and } 47 \\
\text { parents }\end{array}$ & $\begin{array}{l}\text { Attitudes and perceptions } \\
\text { towards spectacle wear }\end{array}$ \\
\hline Isawumi, et al $2014^{53}$ & Nigeria & $\begin{array}{l}\text { Descriptive cross- } \\
\text { sectional }\end{array}$ & 405 respondents & $\begin{array}{l}\text { Perceptions, towards treatment } \\
\text { of childhood strabismus }\end{array}$ \\
\hline Odedra, et al $2008^{55}$ & Tanzania & Qualitative & $\begin{array}{l}8 \text { focus groups } \\
\text { discussion }\end{array}$ & Barriers to spectacle use \\
\hline Mafwiri, et al $2014^{56}$ & Tanzania & Comparison study & 45 Clinical Officers & Accessibility child eye health \\
\hline Chan, et al $2020^{57}$ & South Africa & Qualitative & 93 Children & Attitude and perceptions \\
\hline $\begin{array}{l}\text { Faderin and Ajaiyeoba } \\
200158\end{array}$ & Nigeria & Quantitative & 919 pupils & $\begin{array}{l}\text { Barriers to acceptance of wearing } \\
\text { glasses }\end{array}$ \\
\hline Megbelayin 201359 & Nigeria & Quantitative & 1,241 pupils & $\begin{array}{ll}\text { Barriers to acceptance } & \text { of } \\
\text { prescribed spectacles } & \end{array}$ \\
\hline Kotb, et al $2010^{60}$ & Egypt & Descriptive & 100 children & Attitudes and perception \\
\hline Schulze et al $2014{ }^{61}$ & Malawi & Qualitative study & 58 parents & $\begin{array}{l}\text { Barriers to acceptance of free } \\
\text { pediatric cataract surgery }\end{array}$ \\
\hline Shirima et al $2006^{62}$ & Tanzania & Qualitative study & 117 parents & $\begin{array}{l}\text { Barriers of pediatric cataract } \\
\text { surgery among parents }\end{array}$ \\
\hline Alrasheed $2020^{63}$ & Sudan & Quantitative & 80 schoolteachers & $\begin{array}{l}\text { Teachers' Perspectives about } \\
\text { childhood eye care }\end{array}$ \\
\hline
\end{tabular}




\section{Discussion}

Factors affecting utilization of paediatric eye care services in African countries

Several authors ${ }^{6-22}$ highlighted three main reasons for the high prevalence of childhood VI in Africa which include non-availability, non-accessibility, and non-affordability of eye care services. Studies included in this review acknowledge the fact that even in countries where facilities are available, accessible and affordable barriers such as lack of knowledge, misconception of the consequences of a childhood eye disease and misunderstandings on who to consult for treatment therefore impedes proper utilisation. Moreover, demographics, geographical landscape, and socio-economic status and environmental factors constitute barriers to accessing available and affordable childhood eye care services in African ${ }^{8-32}$.

\section{Availability, accessibility and affordability of pae- diatric eye care services}

Socio-economic factors such as income, employment, and insurance were found to be having positive association with use of the eye care services among communi$\operatorname{ties}^{29,37,38}$. All the highlighted educational and socio-economic status barriers have negative impact on available and accessible childhood eye care services among African poor community.

\section{Availability of paediatric eye care services}

The availability and distribution of eye care professionals is far less in Africa as compared to developed countries with nine times more eye care professionals per million population8-12. Within African countries, availability of paediatric eye services varies from region to region, from district to district and even from one community to another ${ }^{8-32}$. Furthermore, the optometrist to population ratio remains low due to non-prioritisation and/or absence of training institutions within the African continent. The situation is dire even in countries that are reported to have training institutions, which therefore requires policy formulation/review then amendment in order to rectify the inadequate numbers, skewedness, lack of infrastructure, improve knowledge base within the respective countries ${ }^{9}$. The African child strategy forum also reported that eye care services were inadequate and skewed in distribution which impacts negatively on accessibility to these services. ${ }^{5}$ In support, studies from Cameroon 5'9, Ethiopia ${ }^{5}$, Sudan and South Africa ${ }^{5,7}$ acknowledged the skewedness of ophthalmologists distribution being mainly at urban areas as well as few that are working in the public service ${ }^{5-20}$. This worsens the situation particularly among those living in remote areas as they remain sidelined with poor access to eye care services.

School health system in Swaziland does not function optimally due to the lack of human resource, with only two ophthalmic nurses to attend to referred children in the entire country15. The authors ${ }^{14,15,55}$ cited that the reasons of unavailability of paediatric eye care services could be due to poor design/formulation of policy which results in poor functioning health systems in most of African countries that fails to inform eye care policy plans in the respective countries. The levels of care in particular the primary level, therefore needs to be reconfigured in order to ensure adequate distributions of these services.

\section{Accessibility to paediatric eye care services}

Poor accessibility to eye care services is a major factor contributing to the high prevalence of childhood blindness in Africa ${ }^{7-33}$. The common identified barriers for accessing paediatric eye care services among African communities were long distance travelled to appropriate eye care facilities and poor road infrastructure ${ }^{13-60}$. A significant portion of the population (40\%) of Sudan have no access to health services located within $5 \mathrm{~km}$ radius particularly for those residing in rural areas18. Similarly, in Swaziland children with eye problems were referred to another region that offers ophthalmic services, due to the unavailability of a paediatric eye health facility in their region ${ }^{15}$. Consequently, available services in urban areas end up being underutilised while a significant portion of children live with avoidable and treatable eye conditions ${ }^{19-23}$. Nigerian parents expressed that getting time off work, long waiting period at clinic were barriers for accessing paediatric eye care services ${ }^{20}$. The report highlighted that logistics barriers had significant effect on approachability to paediatric eye care and recommended that these obstacles should be considered when planning eye care programs ${ }^{20}$.

A survey conducted in Africa to assess tertiary paediatric eye care services revealed that there are 21 centres located in 10 out of 42 countries $^{13}$. The authors 13 suggested that strengthening existing paediatric eye care services in Africa would need investment in manpower (childhood blindness coordinators, eye care professionals and others stakeholders). In addition, programs to recognise and refer children requiring services and mechanisms to support the reasonably high price of providing this service. Another study in Malawi reported that long distance travelled to health facilities lead to decrease acceptance of free childhood eye services. The 
study concluded that providing eye care services free of cost may not be adequate for the poorest people in rural Africa ${ }^{60}$.

The environment around the people may affect their access to paediatric eye care services. These barriers include difficulties with transportation, great distances to a health centre, long appointment waiting time and other barriers affecting access to childhood eye care, these obstacles were cited by several authors ${ }^{7,13,20,24,39}$ has huge impact on availability and accessibility to paediatric eye care among African communities. A study conducted in South Africa by Mashige, et al. to determine the barriers to access eye care services, $29.1 \%$ of responders stated that they were unable to get treatment due to long waiting times ${ }^{26}$. Another study conducted in Sudan parents were cited lack of transportation and faraway of eye care centre as barriers for accessing childhood eye care services ${ }^{13}$. Parents in Nigeria were reported long waiting periods at the clinic as barriers for accessing a child eye care $^{20}$. This could be due to most people during seeking eye care skip levels and present to higher levels without following referral protocols and turned away sometimes. Furthermore, the poor road infrastructure/poor transport system has been documented as contributing to poor accessibility in many African countries.

\section{Affordability of paediatric eye care services}

The income level of people and the cost of paediatric eye care services influence affordability of eye care services in Africa ${ }^{21-63}$. Poverty is a major problem specifically in poor African nations, therefore, the people are unable to afford the cost of paediatric eye care services, and results in conditions that could have been treated at an early stage being left untreated and may cause visual impairment ${ }^{7-22}$. Africa with approximately 10 percent of world's population and carry 19 percent of the world's blindness, this could be due to a combination of factors such as poverty, lack of education and inadequate eye care services ${ }^{22-63}$. Nigeria is second economic power in Africa $^{20}$, however the blindness in Nigeria is associated with poverty, in part reflecting lower access to servic$\mathrm{es}^{23}$. Studies have reported that cost is a major barrier in accessing paediatric eye care in Nigeria, Sudan and Ethiopia $^{20,24,25}$. They recommended that efforts were needed to create mechanisms that could bridge communities and eye care facilities. Mashige, et al. ${ }^{26}$ conducted a study to determine the utilization of eye care services in South Africa they revealed that $80.5 \%$ of participants received the recommended treatment for their eye conditions, however $36.4 \%$ of respondents reported that they did not get the management due to affordability. South African considerd the leading economy in Africa and also the cost of eye care was cited as main barriers for accessing eye care services. A study conducted in Nigeria to assess the reasons for rescheduling of surgery for paediatric cataract in a tertiary hospital the study showed that the main reason was financial restrictions ${ }^{35}$. The main restriction preventing children in Lagos, Nigeria from using spectacles was affordability58. In Tanzania main barriers for accessing spectacle among children was $\operatorname{cost}^{55}$. So that, when individuals have financial difficulties, their priorities may not be on the prevention and treatment of vision impairment and people of low-income might not have health insurance for covering eye care. In Sudan $72.6 \%$ of participants stated that their health insurance did not cover eye care services ${ }^{24}$. From above mentioned in reviewed studies paediatric eye care services are not supported in African countries and the popultion still suffer to afford as this could be due to prioritization of other health care illnesses than eye health particularly in the public sector. WHO African region reported that regardless of progress improvement of health in many African countries are still on average far from achieving their health financing goals such as the Abuja target of allocating $15 \%$ of government budgets to health. Majority of African countries out-of-pocket costs are still higher than $40 \%$ of the total health expenditure. This figure reflected that in general the health financing systems in Africa are weak and do not ensure sustainable progression and equity in the way funds are collected and invested ${ }^{64}$.

\section{Effect of demographic, social and cultural factors on utilization of paediatric eye care}

These aspects sometime overlap and multi-factorial solutions are needed to address the problem. There are many underlying public health principles that affect availability, accessibility, and affordability of the childhood eye care services in Africa. The health care system needs to be organized to provide primary eye care as an entry point into the health care system. For example, paediatric eye care as an entry point into the primary care system. The childhood eye care should be provided at all health care level to cover prevention and treatment; open an effective communities' communication and eye health knowledge should exist between health care providers and the patients; eye care professionals should use best practices with patients and patients should assume responsibility for their health; and health care access should be provided across the entire lifespan, and no individual should be excluded 
from health care despite any conditions ${ }^{4-17}$. The demographic, such as gender, age, education, socio-economic status, social and cultural factors (human behaviour, thoughts, beliefs, attitudes, knowledge and perceptions) influence the utilization of paediatric eye care services in Africa some of these factors discussed below ${ }^{4,24-62}$.

\section{Knowledge, Attitude and Perception(KAP) barriers}

The educational barriers affect most of population and health care providers; the high level of education associated with positive use of eye care services; people with lower education levels may experience lack of knowledge about the importance of regular eye examinations and find it difficult to know the signs and symptoms of eye disorders4. Many people believe that if they had an eye disease they would have symptoms. The silent eye conditions such as glaucoma and amblyopia are usually difficult to detect even among knowledgeable and well-educated parents hence the study from Swaziland may have found no significant difference.34 WHO reported that major cause of global childhood vision impairment is uncorrected refractive error and estimates that $80 \%$ of vision impairment is avoidable by early diagnosis and management. 1 Therefore, improved awareness of the community about paediatric eye care is very important in developing countries and could help in timely diagnosis and management of eye conditions. In many African countries awareness about childhood eye problem is low resulting in high prevalence of preventable childhood visual impairment ${ }^{12-48}$. In Swaziland majority of eye health professionals reported unawareness of available services by parents as the most common barrier to accessing eye care servic$\mathrm{es}^{39}$. Furthermore, Sukati, et al..$^{34}$ stated that $53.1 \%$ of parents have no knowledge about paediatric eye conditions. Majority of parents in Nigeria reported that they would look for eye examination for their children only when the child has some eye problems ${ }^{40}$. Another study conducted among Nigerian school-aged children to identify eye health myths and misconceptions concluded that most of the children do not have basic information about eye care ${ }^{41}$. A study among Kenyan high school students to determine the Knowledge, Attitudes and Practices (KAP) towards refractive error revealed that almost $39 \%$ of the students have never had an eye examination ${ }^{42}$. Moreover, study carried out among Ethiopian parents concluded that the levels of knowledge towards childhood blindness prevention and treatment were low. Therefore, educational interventions to increase the knowledge on treatment and prevention of childhood blindness are important to reducing the high prevalence of visual impairment in Africa ${ }^{43}$. A study conducted in Kenya to assess the KAP of eye disease in children among pediatricians, revealed that the pediatricians had poor level of knowledge on pediatric eye diseases ${ }^{44}$. In another study conducted among Nigerian guardians to assess attitude towards childhood eye care. The result indicated the negative implications of neglecting eye diseases and use of self and harmful traditional eye-medications by the parents need to be eliminated by suitable eye health educational intervention ${ }^{45}$. Also ignorance of refractive error as barriers reported among Nigerian students58. However, in Ghana 46 almost $76 \%$ of mothers had good knowledge about childhood blindness, the authors concluded that maternal knowledge about paediatric eye care was high. Nevertheless, intervention educational program that concentrate on increasing level of parental awareness of childhood visual impairment are needed ${ }^{46}$. A study in Ethiopia to assess the knowledge, attitude and associated factors towards refractive error among primary school teachers concluded that Knowledge and attitude towards refractive error was low among teachers and recommended that eye health educational program needed for educators ${ }^{47}$. About $94.3 \%$ of Nigerian parents repoted that they commonly use self-medication and local remedies for treatment of conjunctivitis 48 . About $54 \%$ of the respondents visiting a tertiary eye clinic in southern Nigeria had no knowledge of the treatment of the strabismus ${ }^{53}$. Therefore, programs to increase awareness of causes of eye diseases and dangerous effects of self-medication are necessary for the community ${ }^{48}$. Parents in Tanzania reported that cataract mainly related to old age, the majority of parents expressed astonishment at the diagnosis, as they were not aware a child could have cataract ${ }^{61}$. Government and NGOs in Africa should deliver childhood eye care education through the public media, radio, television, social media and newspaper, to improve awareness of community about childhood eye care services and understand the importance of early diagnosis and treatment of paediatric eye condition.

Several authors ${ }^{42,49,50,51,52}$ reported that the attitudes and perceptions towards eye care and spectacles for correcting refractive error were the main barriers for accessing pediatric eye care in developing countries. In many African communities' parents believe that young children should not wear spectacles, regarding to their perception strabismus was considered as irreversible eye condition. Alrasheed, et al ${ }^{24}$ revealed that about $45.6 \%$ of parents from South Darfur State of Sudan believe that 
strabismus is an untreatable eye condition. Moreover, about $14 \%$ of the parents showed that local remedies of strabismus are more effective than the treatment in the hospital. Whilst other parents believed that childhood eye diseases, does not require treatment and could resolve spontaneously. In Nigeria, about $21.33 \%$ of parents reported that they ignored looking for healthcare for childhood eye diseases and almost $9.26 \%$ and $7.76 \%$ reported that they use self-medication and local remedies, respectively for treatment of pediatric eye condition ${ }^{45}$. Reasons for using self-medication/ local remedies in treatment of childhood eye problems could be due to inadequate paediatric eye care services, higher cost, and cultural beliefs, combined with low levels of education. In Sudan, learners believed that wearing spectacles affected their opportunities for education, employment and marriage ${ }^{51}$. Alrasheed, et al ${ }^{51}$ suggested that paediatric eye health education packages should be broadcast through the public media to promote attitudes, perception and benefits about spectacle wear and eye care.

Parents in Nigeria stated that using spectacles would damage their children's eyes45. While others believed that glasses were meant for old people53. Parents in Sudan reported that the disadvantages of wearing spectacles could lead to development of poor eye sight and spectacle wear had psychological impact, particularly among females ${ }^{51,62}$. Students in Tanzania were happy with appearance of their eye glasses and the valuable effect on their vision, but their parents were concern about safety of spectacle wear ${ }^{54}$. Consequently, health education and enlightenment strategies should be put in place by professional bodies and the government to increase parent's attitude and perception towards childhood eye care services ${ }^{40}$. A study conducted among visually impaired children in South Africa to know disability related distress due to uncorrected refractive error (URE) indicated that vision impairment due to URE can cause distress in different domains in children. The study recommended that distresses due to URE should be taken into consideration when developing paediatric eye care strategy ${ }^{56}$. Study conducted among schoolaged children in Egypt revealed that visual impairment has impact on self-confidence and quality of life and recommended that it is critical for planning and implementing of a psychological counseling platform for children with visual impairment to improve their emotional condition ${ }^{59}$. As highlighted above from reviewed articles the fear, stigma and bad perceptions about paediatric eye care services are commonly experienced among Africa communities. Therefore, paediatric eye care education platforms should be delivered through the public media to encourage awareness and benefits about eye care.

\section{Conclusion}

The main barriers to accessing paediatric eye care services in Africa were non-availability, non-accessibility, and non-affordability, lack of knowledge, negative attitudes of parents and primary health system. In terms of accessibility to the health care, previous studies, indicate that a high proportion health services are concentrated in the capital cities. Furthermore, there was a huge disparity in the distribution of healthcare providers in the various States in African nations. Hence, paediatric eye care plan with school-based eye-care interventions could have great effect to reduce barriers to accessing eye care. Teachers, nurses and trained personals could help to provide school vision screenings, particularly in some African countries where there is a marked lack of eye care professionals. The studies reviewed revealed that there are others factors affecting the utilization of paediatric eye services which included the public health system and the demographic characteristics of population such as educational level, socio-economic status, misconception as well as the environment around the people. Barriers to accessing paediatric eye care services are broad and some are interrelated, it is better to address when interventions are applied in combination, as no single aspect addresses all barriers in order for eye health services to be available, accessible, appropriate and acceptable. Strategy is needed for improving knowledge, attitudes and practices of the key stakeholders such as parents and teachers could play a crucial role in addressing these barriers. There is therefore a need for all relevant stakeholders to play a significant role in addressing barriers to child eye care in African countries.

\section{Acknowledgement}

The author would like to thank Dr Godwin Ovenseri-Ogbomo for his help in editing the manuscript.

\section{Financial support and sponsorship}

Nil.

\section{Declaration}

The authors declare that they have no financial or personal relationships that may have inappropriately influenced them in writing this article. 


\section{References}

1. Pascolini D, Mariotti SP. Global estimates of visual impairment: 2010. British Journal of Ophthalmology. 2012 May 1;96(5):614-618.

2. Alrasheed SH, Naidoo KS, Clarke-Farr PC. Prevalence of visual impairment and refractive error in school-aged children in South Darfur State of Sudan. Afr Vision Eye Health. 2016;75(1), a355. http://dx.doi. org/10.4102/ aveh. v75i1.355

3. Courtright P, Hutchinson AK, Lewallen S. Visual impairment in children in middle-and lower income countries. Archives of Disease in Childhood. 2011 Dec 1;96(12):1129-1134.

4. Frazier M, Kleinsten R. Access and barriers to health care. Optometric Care within the Public Health Community. Cadyville, NY: Old Post Publishing. 2009:1-9.

5. Borrel A, Dabideen R, Mekonen Y, Overland L. Child eye health in Africa: The status and way forward. The African Child Policy Forum. ORBIS Africa, Cape Town. 2013:1-37.

6. Balasubramaniam SM, Kumar DS, Kumaran SE, Ramani KK. Factors affecting eye care-seeking behaviour of parents for their children. Optometry and Vision Science. 2013 Oct 1;90(10):1138-1142.

7. Ntsoane MD, Oduntan OA. A review of factors influencing the utilization of eye care services. African $\mathrm{V} i$ sion and Eye Health. 2010 Dec 12;69(4):182-192.

8. Naidoo K, Savage B, Westerfall B. Creating a sustainable spectacle delivery solution. Vision 15 July/ August 2006 .

9. Oduntan OA, Mashige KP, Kio FE, Boadi-Kusi SB. Optometric education in Africa: Historical perspectives and challenges. Optometry and Vision Science. 2014 Mar 1;91(3):359-365.

10. Gilbert C, Foster A. Childhood blindness in the context of VISION 2020: the right to sight. Bulletin of the World Health Organization. 2001; 79:227-232.

11. Adio AO, Komolafe RD. The State of Paediatric Eye Care in Nigeria: A Situational Review and Call for Action. Nigerian Health Journal. 2013;13(1):1-6.

12. Gogate P, Kalua K, Courtright P. Blindness in childhood in developing countries: time for a reassessment. PLoS Medicine. 2009 Dec 8;6(12): e1000177.

13. Agarwal PK, Bowman R, Courtright P. Child eye health tertiary facilities in Africa. Journal of American Association for Paediatric Ophthalmology and Strabismus. 2010 Jun 1;14(3):263-266.

14. Alrasheed SH, Naidoo KS, Clarke-Farr PC, Binnawi $\mathrm{KH}$. Building consensus for the development of child eye care services in South Darfur State in Sudan using the Delphi technique. African Journal of Primary Health Care \& Family Medicine. 2018;10(1):1-9.

15. Sukati VN, Moodley VR, Mashige KP. A situational analysis of eye care services in Swaziland. Journal of Public Health in Africa. 2018 Dec 21;9(3):167-172.

16. Silva JC, Bateman JB, Contreras F. Eye disease and care in Latin America and the Caribbean. Survey of Ophthalmology. 2002 May 1;47(3):267-274.

17. Kishiki E, Van Dijk K, Courtright P. Strategies to improve follow-up of children after surgery for cataract: findings from Child Eye Health Tertiary Facilities in sub-Saharan Africa and South Asia. Eye. 2016 Sep;30(9):1234-1241

18. World Health Organization. Saving the lives of the mother and children. Rising to the challenge. Khartoum: WHO; 2013. WRH/WP/13.16.

19. Fafowora OF. Prevalence of blindness in a rural ophthalmically underserved Nigerian community. West African Journal of Medicine. 1995 Dec;15(4):228-231.

20. Ebeigbe JA. Factors influencing eye-care seeking behaviour of parents for their children in Nigeria. Clinical and Experimental Optometry. 2018 Jul;101(4):560-564. 21. Robin AL, Nirmalan PK, Krishnadas R, Ramakrishnan R, Katz J, Tielsch J, Thulasiraj RD, Friedman DS. The utilization of eye care services by persons with glaucoma in rural south India. Transactions of the American Ophthalmological Society. 2004 Dec; (102):47-55.

22. Naidoo K. Poverty and blindness in Africa. Clinical and Experimental Optometry. 2007 Nov 1;90(6):415-421.

23. Tafida A, Kyari F, Abdull MM, Sivasubramaniam S, Murthy GV, Kana I, Gilbert CE, Nigeria National Survey of Blindness and Visual Impairment Study Group. Poverty and blindness in Nigeria: results from the national survey of blindness and visual impairment. Ophthalmic Epidemiology. 2015 Sep 3;22(5):333-341.

24. Alrasheed SH, Naidoo KS, Clarke-Farr PC. Childhood eye care services in South Darfur State of Sudan: Learner and parent perspectives. African Vision and Eye Health. 2016 Jan 1;75(1):1-3.

25. Melese M, Alemayehu W, Friedlander E, Courtright P. Indirect costs associated with accessing eye care services as a barrier to service use in Ethiopia. Tropical Medicine \& International Health. 2004 Mar 1;9(3):426-431.

26. Mashige KP, Martin C. Utilization of eye care services by elderly persons in the northern Ethekwini district of Kwa-Zulu-Natal province, South Africa. African Vision and Eye Health. 2011 Nov 12;70(4):175-181.

27. Kovai V, Krishnaiah S, Shamanna BR, Thomas R, Rao GN. Barriers to accessing eye care services among visually impaired populations in rural Andhra Pradesh, 
South India. Indian Journal of Ophthalmology. 2007 Sep;55(5):365-371.

28. Robin AL, Nirmalan PK, Krishnadas R, Ramakrishnan R, Katz J, Tielsch J, Thulasiraj RD, Friedman DS. The utilization of eye care services by persons with glaucoma in rural south India. Transactions of the American Ophthalmological Society. 2004 Dec; (102):47-56

29. Schaumberg DA, Christen WG, Glynn RJ, Buring JE. Demographic predictors of eye care utilization among women. Medical Care. 2000 Jun 1 and 38(6):638646.

30. Kuang TM, Tsai SY, Hsu WM, Cheng CY, Liu JH, Chou P. Correctable visual impairment in an elderly Chinese population in Taiwan: The Shihpai Eye Study. Investigative Ophthalmology \& Visual Science. 2007 Mar 1;48(3):1032-1037.

31. Fletcher AE, Donoghue M, Devavaram J, Thulasiraj RD, Scott S, Abdalla M, Shanmugham CA, Murugan PB. Low uptake of eye services in rural India: a challenge for programs of blindness prevention. Archives of Ophthalmology. 1999 Oct 1;117(10):1393-1399.

32. Courtright P, Bassett K. Gender and blindness: eye disease and the use of eye care services. Community Eye Health. 2003;16(45):11-12.

33. Nirmalan PK, Katz J, Robin AL, Krishnadas R, Ramakrishnan R, Thulasiraj RD, Tielsch J. Utilisation of eye care services in rural south India: The Aravind Comprehensive Eye Survey. British Journal of Ophthalmology. 2004 Oct 1;88(10):1237-1241.

34. Sukati VN, Moodley VR, Mashige KP. Knowledge and practices of parents about child eye health care in the public sector in Swaziland. Afr J Prm Health Care Fam Med. 2018;10(1), a1808. https://doi.org/10.4102/ phcfm. v10i1.1808

35. Ugalahi MO, Olusanya BA, Fagbemi OO, Baiyeroju AM. Delays in uptake of surgery for childhood cataract at a child eye health tertiary facility in sub-Saharan Africa. European Journal of Ophthalmology. 2020 Mar;30(2):280-283.

36. Chan VF, Minto H, Mashayo E, Naidoo KS. Improving eye health using a child-to-child approach in Bariadi, Tanzania. Afr Vision Eye Health. 2017;76(1), a406. https://doi. org/10.4102/aveh. v76i1.406

37. Zhang X, Andersen R, Saaddine JB, Beckles GL, Duenas MR, Lee PP. Measuring access to eye care: a public health perspective. Ophthalmic Epidemiology. 2008 Jan 1;15(6):418-125.

38. Zhang X, Lee PP, Thompson TJ, Sharma S, Barker L, Geiss LS, Imperatore G, Gregg EW, Zhang X, Saaddine JB. Health insurance coverage and use of eye care services. Archives of Ophthalmology. 2008 Aug 11;126(8):1121-1126.

39. Sukati V, Moodley VR, Mashige KP. Knowledge and practices of eye health professionals about the availability and accessibility of child eye care services in the public sector in Swaziland. Afr Vision Eye Health. 2019;78(1), a471. https://doi.org/10.4102/ aveh. v78i1.471

40. Amiebenomo OM, Achugwo DC, Abah I. Parental knowledge and attitude to children's eye care services. Nigerian Journal of Paediatrics. 2016;43(3):215-220.

41. Oguego N, Okoye OI, Okoye O, Uche N, Aghaji A, Maduka-Okafor F, Onyekonwu C, Ezegwui I, Umeh R. Eye health myths, misconceptions and facts: results of a cross-sectional survey among Nigerian school children. Fam Med Prim Care Rev. 2018; 20(2): 144-148, doi: https://doi.org/10.5114/fmpcr.2018.76458.

42. Nyamai LA, Kanyata D, Njambi L, Njuguna M. Knowledge, attitude and practice on refractive error among students attending public high schools in Nairobi County. JOECSA. 2016 Sep 23;20(1):35-41.

43. Belaynew W'T, Berihun MZ, Tadesse AA, Yared AW. Knowledge and practice on childhood blindness among communities in Northwest Ethiopia: implications to blindness prevention programs. JOECSA. 2014 Dec 31;17(2).50-58.

44. Wanyama SP. Knowledge, attitude and practice of eye diseases in children among pediatricians in Kenya (Doctoral dissertation, University of Nairobi).

45. Ayanniyi AA, Olatunji FO, Mahmoud AO, Ayanniyi RO. Knowledge and attitude of guardians towards eye health of primary school pupils in Ilorin, Nigeria. Niger Postgrad Med J. 2010 Mar;17(1):1-5.

46. Kumah DB, Abdul-Kabir M, Kobia-Acquah E, Amponsah MA, Ablordeppey RK et al. (2017) Knowledge of Childhood Blindness among Mothers Visiting a Children's Hospital in the Kumasi Metropolis, Ghana. Adv Ophthalmol Vis Syst 7(3): 00221. DOI: 10.15406/ aovs.2017.07.00221

47. Alemayehu AM, Belete GT, Adimassu NF. Knowledge, attitude and associated factors among primary school teachers regarding refractive error in school children in Gondar city, Northwest Ethiopia. PloS One. 2018 Feb 15;13(2):e0191199.

48. Ebeigbe JA, Emedike CM. Parents' awareness and perception of children's eye diseases in Nigeria. Journal of Optometry. 2017 Apr 1;10(2):104-110.

49. Dhoble P, Agarwal R, Patel C, Anand G, Sharma J, Sabde Y. Study to assess the psychosocial aspects of refractive errors and effectiveness of health education in correcting stigmas related to spectacle use in 
high-school students of rural India. Int J Med Sci Public Health. 2013;2(3):716-719. https://doi.org/10.5455/ ijmsph.2013.060520131

50. Castanon Holguin AM, Congdon N, Patel N, et al. Factors associated with spectacle-wear compliance in school-aged Mexican children. Invest Ophthalmol Vis Sci. 2006;47(3):925-928. https://doi.org/10.1167/iovs.050895

51. Alrasheed SH, Naidoo KS, Clarke-Farr PC. Attitudes and perceptions of Sudanese high-school students and their parents towards spectacle wear. Afr Vision Eye Health. 2018;77(1), a392. https://doi.org/10.4102/ aveh. v77i1.392

52. Nirmalan PK, Sheeladevi S, Tamilselvi V, Victor AC, Vijayalakshmi P, Rahmathullah L. Perceptions of eye diseases and eye care needs of children among parents in rural south India: The Kariapatti Pediatric Eye Evaluation Project (KEEP). Indian Journal of Ophthalmology. 2004 Jun 1;52(2):163-167.

53. Isawumi MA, Ulaikere $M$, Adejumo OO, Adebayo M, Kekunnaya M. Awareness, perceptions and knowledge of strabismus among patients visiting a tertiary eye clinic in Southwest Nigeria. Int Ophthalmol. 2014;34(5):1034-1042.

54. Ebeigbe JA, Kio F, Okafor LI. Attitude and beliefs of Nigerian undergraduates to spectacle wear. Ghana Med J. 2013;47(2):70-73.

55. Odedra N, Wedner SH, Shigongo Z, Nyalali K, Gilbert C. Barriers to spectacle use in Tanzanian secondary school students. Ophthalmic Epidemiology. 2008 Jan 1;15(6):410-417.

56. Mafwiri MM, Kisenge R, Gilbert CE. A pilot study to evaluate incorporating eye care for children into re- productive and child health services in Dar-es-Salaam, Tanzania: a historical comparison study. BMC Nursing. 2014 Dec;13(1):1-11.

57. Chan VF, Singer S, Naidoo KS. Disability-related-distress in primary school learners with vision impairment due to uncorrected refractive error in KwaZulu-Natal Province, South Africa-a qualitative study. PLoS One. 2020 Mar 3;15(3): e0229108.

58. Faderin MA, Ajaiyeoba AI. Barriers to wearing glasses among primary school children in Lagos, Nigeria. Nigerian Journal of Ophthalmology. 2001;9(1):15-19.

59. Megbelayin EO. Barriers to uptake of prescribed refractive spectacles amongst Nigerian students. Int Res J Basic Clin Stud. 2013;1(5):71-77.

60. Kotb SA, Gadallah MA, Marzouk SA. Self-esteem and quality of life among visually impaired children in Assiut City, Egypt. Journal of American Science. 2011;7(8):47-57.

61. Schulze Schwering M, Finger RP, Barrows J, Nyrenda M, Kalua K. Barriers to uptake of free pediatric cataract surgery in Malawi. Ophthalmic epidemiology. 2014 Jun 1;21(3):138-143.

62. Shirima S, Bronsard A, Geneau R. Why are children with cataracts brought late for surgery? Qualitative Findings from Tanzania. In Global Indigenous Health Research Symposium Report 2006 (p. 83).

63. Alrasheed SH. Effect of Binocular Vision Problems on Childhood Academic Performance and Teachers' Perspective. Pakistan Journal of Ophthalmology. 2020 Mar 17;36(2):162-167.

64. Musango L, Elovainio R, Nabyonga J, Toure B. The state of health financing in the African Region. Health Monitor. 2013 Mar;16(9):1-53. 